Neurosurg Focus 4 (5):Article 3, 1998

\title{
Treatment options and time course for intramedullary spinal cord metastasis Report of three cases and review of the literature
}

\author{
Bernhard Sutter, M.D., Adam Arthur, B.A., Jeffrey Laurent, B.S., James Chadduck, M.D., Gerhard Friehs, M.D., \\ Georg Clarici, M.D., and Gerhard Pendl, M.D.
}

Karl Franzens University, Graz School of Medicine, Department of Neurosurgery, Graz, Austria; and University of Virginia, Department of Neurosurgery, Charlottesville, Virginia

Surgical treatment of intrameduallary spinal cord metastases (ISCM) has become increasingly effective in recent years. The advent of new imaging techniques combined with an enhanced understanding of the natural history of these tumors has improved the effectiveness of the available treatment options. The authors present three new cases of ISCM successfully treated with surgery. A review of 129 cases found in the literature is also discussed. Characteristic symptomology and presentation are reviewed with an eye toward improving diagnostic methodology. The natural history of ISCM is divided into three phases. Surgical intervention should be used early in phase 2 .

Key Words * intramedullary * tumor * metastasis * microsurgery * spinal cord

It is only within the last 15 years, since the development of magnetic resonance (MR) imaging, that surgical treatment of intramedullary spinal cord metastases (ISCM) has become a more precise treatment option. Developments in imaging now allow reliable diagnosis, and the advent of surgical microscopy has brought these tumors into the domain of neurosurgical care. Clinical case reports appearing in the literature have come to augment the existing autopsy-based reports. Consensus on the average time course and proper treatment modalities is becoming more clear. Treatment choices should involve analysis of possible benefits from surgical intervention (that is, pain relief, ambulation, alleviation of incontinence) over the course of the patient's life expectancy. In this paper we present three patients whose ISCM were surgically treated and a review of all patient series in the literature.

\section{CASE REPORTS}

\section{Case 1}

This 40-year-old woman with a history of breast cancer treated by mastectomy and chemotherapy was admitted to the neurology service at an outside hospital with new onset of left leg pain in the L4-S1 dermatomes. She developed progressive paraparesis and urinary retention during the ensuing 10 days. The results of a myelogram of the lumbar spine were negative, as were computerized tomography scans of the lumbar spine and head. Cerebrospinal fluid (CSF) analysis from a lumbar puncture showed a protein level of $55 \mathrm{mg} / \mathrm{dl}$, glucose of $60 \mathrm{mg} / \mathrm{dl}$ and $4 / 3$ lymphocytes $/ \mathrm{mm}^{3}$ with no erythrocytes. The results of cytological examination were negative. An MR image demonstrated a small solitary intramedullary tumor with a large cystic component in the T11-12 region (Fig. 1); no other sites of tumor were identified during an extensive metastatic workup. The cystic component of this tumor was thought to be the cause of the patient's rapid loss of neurological function. She was given high-dose steroids and taken to the operating room where a total T11-12 laminectomy and gross-total resection of the tumor and cyst wall were performed. Histological examination revealed a tumor of ductile mammacarcinomatous origin. 


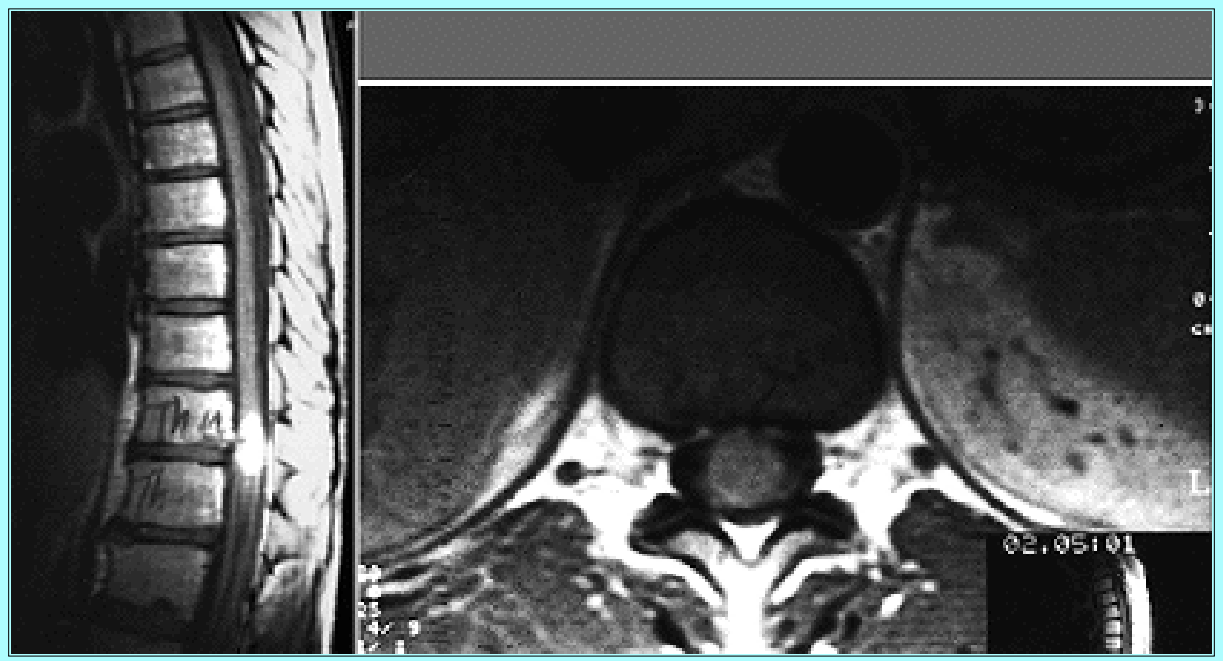

Fig. 1. Case 1. Sagittal (left) and axial (right) MR images showing a small intramedullary tumor with a large cystic component in the T11-12 region.

Postoperatively the patient recovered slowly from the paraparesis so that she was able to ambulate without assistance; however, her urinary retention continued. She underwent chemotherapy with cyclophosphamide, methotrexate, and 5-fluorouracil and additional radiotherapy. She did well for 11 months when she again developed progressive weakness in the lower extremities. An MR image revealed a local recurrence at T11-12 (Fig. 2). The patient refused further surgical treatment, developed dense hemiparesis, becoming nonambulatory at 17 months postoperatively, and died 2 months later from widespread metastatic disease.

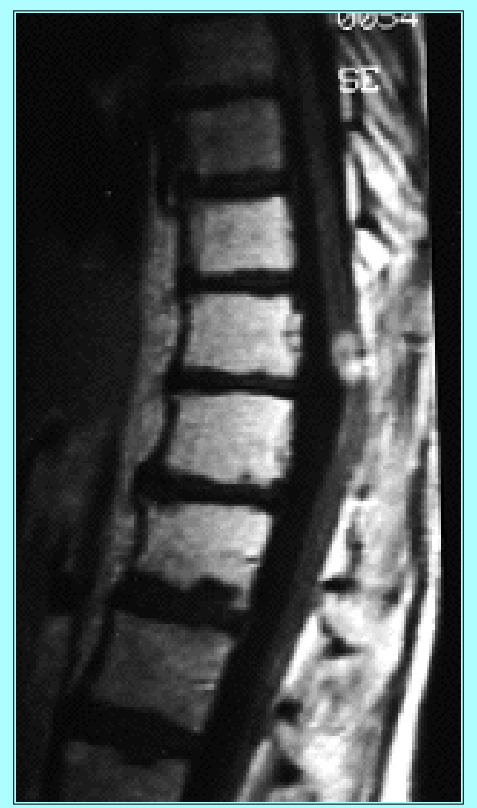

Fig. 2. Case 1. Longitudinal MR image revealing local recurrence in the T11-12 region 11 months after gross-total resection.

\section{Case 2}

This 54-year-old man with a 3-month history of numbness and a 1-month history of progressive ataxia and weakness in the lower extremities was admitted to the neurology service; his symptoms progressed to include urinary retention and dense hemiparesis over a 4-day hospital course. An MR image demonstrated a small solid tumor at T11-12 (Fig. 3). He was given high-dose steroids, and a metastatic workup revealed a suspicious lesion in the right lung. Bronchoscopy and examination of a biopsy specimen demonstrated a bronchial carcinoma of large cell origin. The prognosis was quite poor, but the possibility for independent ambulation led us to offer surgery. A total T11-12 laminectomy was performed, and subtotal resection of the tumor was achieved secondary to the infiltrative/nonencapsulated nature of this tumor. Histological examination revealed a large cell carcinoma of bronchial origin. Postoperatively the patient was able to ambulate without assistance until his death 6 months later from complications of his primary tumor. An autopsy demonstrated no significant increase in the size of the intramedullary spinal cord tumor. 


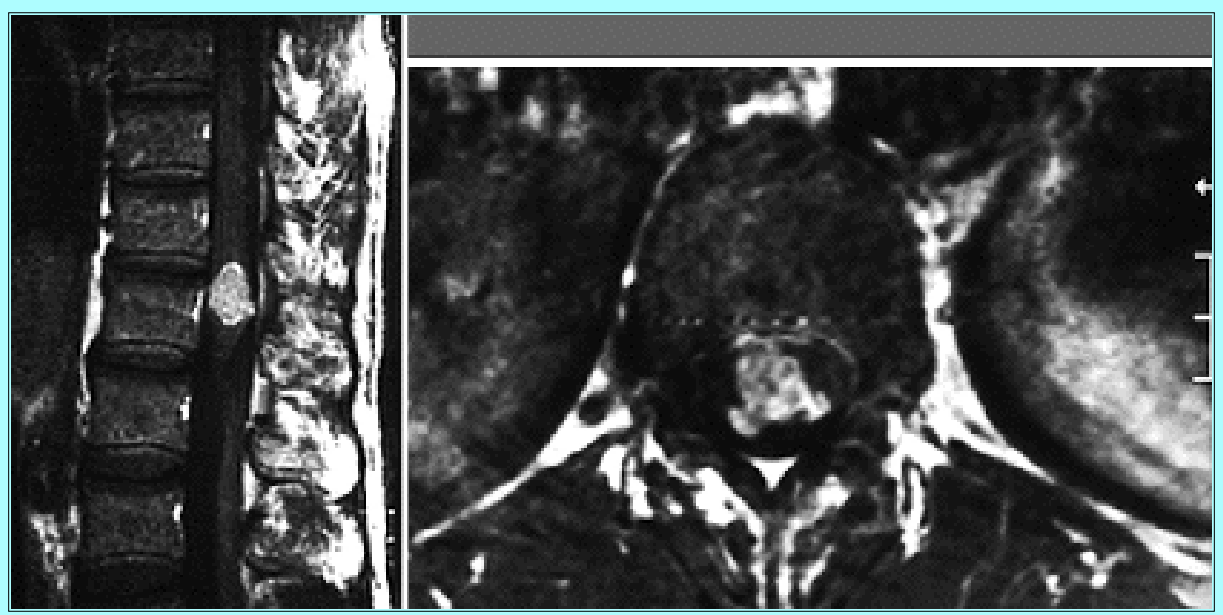

Fig. 3. Case 2. Sagittal (left) and axial (right) MR images demonstrating a small solid tumor at T11-12.

\section{Case 3}

This 45-year-old man presented to the neurology service with a 6-month history of dysesthesia, tingling bilaterally in the lower extremities, and a 3-week history of mild paraparesis. During a 6-day period he developed bowel and bladder incontinence and inability to ambulate. An MR image of the spine revealed an expansive lesion in the conus medullaris (Fig. 4). The patient underwent a total T12-L2 laminectomy and the soft tumor mass was resected; a gross subtotal resection was achieved. Histological examination demonstrated oat-cell carcinoma. The primary tumor was then discovered in the patient's lung. Postoperatively the patient did quite well, regaining bowel and bladder function within the 1st week and then was able to walk independently within 4 days. The patient died 8 months postoperatively from complications of the primary tumor.

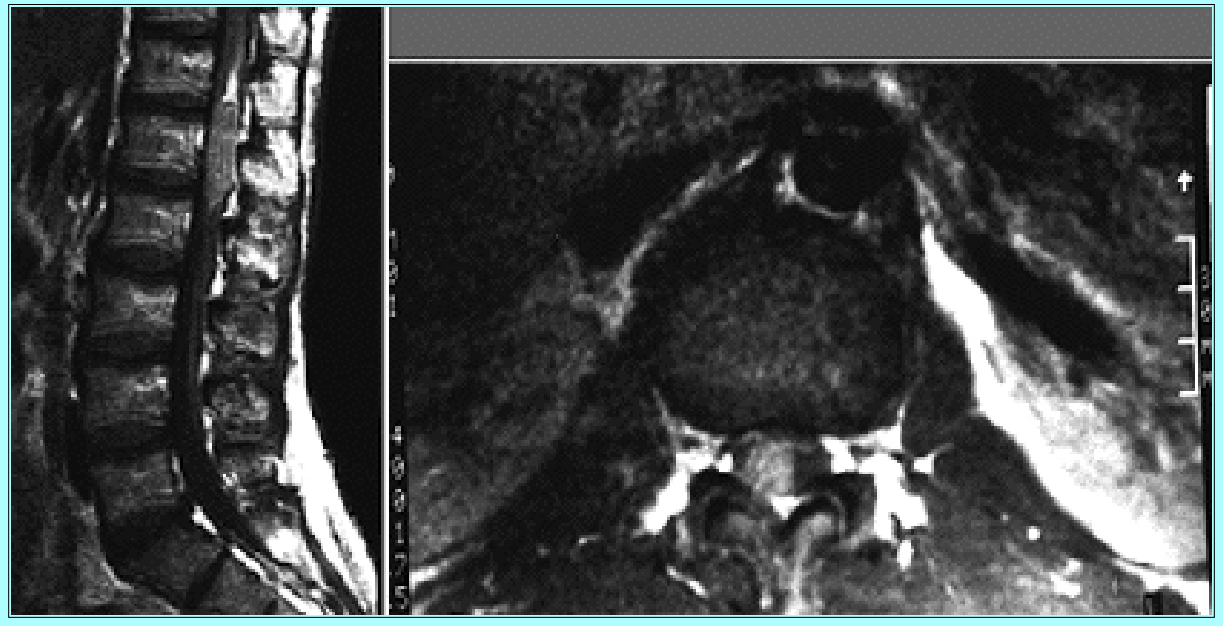

Fig. 4. Case 3. Sagittal (left) and axial (right) MR images showing an expansive lesion in the conus that was subtotally resected. Histological examination demonstrated that the tumor was oat-cell carcinoma.

\section{DISCUSSION}

Buchholz first described metastases in the spinal cord parenchyma in 1897. Authors of autopsy studies estimate the frequency of ISCM to be as high as $2.1 \%$ of all cases of systemic cancer.[2,4,6,12] After surveying the literature, we found 129 cases in which intramedullary tumors were reported as metastases. Most were treated with radiotherapy or chemotherapy, whereas eight were treated with surgery, including our three current cases.[1,4-25]

The first controversial issue regarding the natural history of these metastases is the mechanism of transportation from primary site to spinal cord. Several parallel routes have been postulated, including hematogenous dissemination, through either the arterial supply to the spinal cord or retrograde spread from the venous system, and direct extension along nerve roots or perineural sheaths. $[12,15]$ Weissman and Grossman[24] have hypothesized that spreading may occur through the central canal, which may be dilated by tumor-induced hydrocephalus. Spread via the CSF pathways and direct extension certainly occur, but hematogenous routes probably account for most ISCM. $[9,12]$

Edelson, et al.,[6] have posited that the spinal cord is more susceptible to metastatic invasion than the brain, based on the incidence of patients with ISCM compared with those with brain metastases. Costigan and Winkelman[4] have countered that 
these incidence rates fail to take multiple metastases into account and therefore may be misleading. Because the lung is the site of a significant number of primary cancers, venous drainage patterns may also play a role in the relatively large numbers of patients presenting with ISCM. It has been reported that 40 to $60 \%$ of ISCM are secondary to lung cancer, followed by breast cancer with a frequency of approximately $14 \% \cdot[2,6,9,12]$ All surgical reports of ISCM come from lung or breast primary cancers, except one case of mixed follicular papillary thyroid metastasis. $[5,7,21,25]$

Diagnosis of an intramedullary tumor without benefit of an MR image can be difficult. The most common presenting symptoms were pain and weakness, followed by paresthesias and bowel and bladder dysfunction. $[6,9,18,20,25]$ The distribution of the weakness was asymmetric in most patients with ISCM. $[9,18,20,25]$ Other common findings included a diminished sensory level, pathological reflexes, and Brown-Séquard's syndrome.[6,9,11,18,20,25] Many researchers have asserted that root pain is characteristic of extramedullary and not intramedullary tumors; $[6,20,23]$ however, exceptions certainly exist. The patient in Case 1 is notable in this regard. Radicular pain was seen as a presenting symptom in 25 to $33 \%$ of patients.[6,9,12,23]

A number of "noncompressive" myelopathies occur in cancer patients that have similar presentations. The differential diagnosis should include radiation myelopathy, paraneoplastic necrotizing myelopathy, and meningeal carcinomatosis.[12,25] Factors useful in making a diagnosis include pain on presentation, time course, and CSF cytology. Radiation myelopathy and necrotizing myelopathy typically do not present with pain.[25] The progression of neurological deficits is extremely rapid with ISCM, whereas it is more insidious for these other conditions. Cerebrospinal fluid findings in ISCM are usually negative or show only an increase in protein and a mild pleocytosis. $[4,6,9,12,25]$ If positive, meningeal involvement may have occurred. Obviously, all of these factors are important, but MR imaging should still be performed.

Advances in imaging have simplified the diagnosis of ISCM more than any other factor. Plain roentgenography has only been useful in diagnosing neoplasms that deform bone through intrusion or slow pressure. Intramedullary spinal cord metastases, as fast-growing neoplasms, rarely deform surrounding bone and are difficult to see on plain x-ray films. Prior to the widespread availability of MR imaging, myelography was the imaging test of choice for ISCM. When positive, myelography usually shows a symmetric fusiform expansion of the cord over multiple levels or a focal, well-demarcated mass. $[6,9,16,18,20]$ The limitations of myelography are well recognized, with a documented false-negative rate between 40 and 50\%.[3,6,9,12,18,24] Myelographic features atypical of ISCM, such as an asymmetric bulge, occur in up to $30 \%$ of patients with spinal cord lesions. $[3,6,18]$ Postmyelography computerized tomography scans delineate multiple discrete masses better than myelography alone and have also proved useful for obtaining percutaneous biopsy samples.[18]

Properly used, MR imaging is the most sensitive and specific test for the detection of ISCM $[3,8,13,18,23]$ and is the test of choice. Widening of the cord is seen best on sagittal $\mathrm{T}_{1}$-weighted images, $[13,18]$ and $\mathrm{T}_{2}$-weighted images of ISCM show high-intensity signal.[13,18] Kamholtz and Sze[13] have asserted that a normal $\mathrm{T}_{2}$-weighted image can generally exclude intramedullary metastases. In addition, the use of gadolinium-enhanced MR images has further improved sensitivity.[8,13] Gadolinium contrast studies help to distinguish metastatic tumor sites from surrounding edema, which can help localize sites for surgical planning.[13] Magnetic resonance imaging is also effective at helping to discern the response to therapy and the presence of multiple metastatic lesions in the neuraxis.[18]

Sudden onset of neurological deficit and rapid progression are the most consistent characteristics of ISCM. The average time interval from onset to the development of full neurological signs is less than 1 month.[7,12] Retrospectively, most patients recalled earlier, less alarming symptoms that were ignored. In our cases there is evidence of slowly worsening symptoms leading up to a rapid decline in function, which caused the patients to seek treatment. The progression can be conceptualized as occurring in three phases. The first is the time from the first appearance of symptoms, usually ignored or undiagnosed, until the appearance of serious spinal cord symptoms such as paraparesis, incontinence, and urinary retention; this phase usually lasts less than 1 month;[6,7,12] the second begins at presentation and lasts until complete paraplegia and lasts less than 1 month in $75 \%$ of cases; $[9,12]$ the third is the period between paraplegia and death.

Three treatment modalities are available for intramedullary metastases: radiation therapy, chemotherapy, and surgery. The standard therapy is radiation treatment, with or without steroids. $[3,6,9,11,12,23]$ There are some reports of long-lasting remission with radiation, but these are limited to patients in whom a very early diagnosis was made or who had radiosensitive tumors such as oat-cell carcinoma or lymphoma.[3,9,11,16,23,25] Other patients had improvement of their neurological symptoms without an increase in survival time. Eighty percent of patients were paraplegic or dead within 6 months after standard radiation treatment. $[3,4,6,9,12]$ Treatment with steroids offered no additional survival benefit when combined with radiation therapy.[9]

Studies on the efficacy of chemotherapy are limited but show no effect on survival.[11] Holoye, et al.,[11] have described tumor ablation with cyclophosphamide, methotrexate, and lomustine, but neurological deficits and survival remained unchanged. 
Weissman and Grossman[24] have recommended treatment with both intrathecal chemotherapy and radiotherapy in patients with ISCM or meningeal carcinomatosis from oat cell.

Surgery has become an option in an increasing number of cases because of increased rapidity and accuracy of diagnostic imaging and advances in microsurgical techniques.[5,7] Surgical removal is limited by the fact that these masses tend to present after disease is widespread. The opportunity to improve neurological status and survival in patients with ISCM through surgery exists. $[9,23]$ Table 1 summarizes the surgical methods and outcomes of the three new cases reported in this study as well as five cases from the literature.

TABLE 1

REVIEW OF CASE RE PORTS OF PATIENTS WITH ISCM WHO UNDERWENT SURGERY*

\begin{tabular}{|c|c|c|c|c|}
\hline Authors \& Year & $\begin{array}{l}\text { Primary Cancer Sitel Presur- } \\
\text { gical Neurological Sym ptons }\end{array}$ & Resection Tectnique & Aduvart Thera py & Neurdogical Outcome \& Survival \\
\hline $\begin{array}{l}\text { Decker, et al., } \\
1987\end{array}$ & $\begin{array}{l}\text { treast carcinom a.ber vical, } \\
\text { in tersca pular, \& radicular } \\
\text { trachial pain }\end{array}$ & $\mathrm{CO}_{2}$ laser & $\begin{array}{l}\text { RT combined } w / \\
\text { chemo }\end{array}$ & $\begin{array}{l}\text { dysstereognosis \& num tness of } \\
\text { trunk \& LF; working at } 15 \text { mos fol- } \\
\text { lo w up; spine MR mas norm al }\end{array}$ \\
\hline \multirow[t]{2}{*}{$\begin{array}{l}\text { Findlay, et al., } \\
1987\end{array}$} & $\begin{array}{l}\text { unknown/ned pain, rt-sided } \\
\text { meakness, difficulty' woiding }\end{array}$ & $\begin{array}{l}\text { near-total macro- } \\
\text { scopic w' extensi ve } \\
\text { m yelotom y \& CUSA }\end{array}$ & cervical spine RT & $\begin{array}{l}\text { dramatic im provement; regained } \\
\text { ambulation w/mild weakness; } \\
\text { death from systemic disease at } \\
10 \text { mos }\end{array}$ \\
\hline & $\begin{array}{l}\text { lung ade nocarcinomait- } \\
\text { sided meakness, syncope, } \\
\text { \& weight loss }\end{array}$ & $\begin{array}{l}\text { gross-total microsur- } \\
\text { gical technique }\end{array}$ & cervical spine RT & alive $\&$ well at 3 -mo follow up \\
\hline $\begin{array}{l}\text { Mónkelmann, } \\
\text { et al., } 1987\end{array}$ & $\begin{array}{l}\text { thyroid/progressive quadra- } \\
\text { paresis \& neck pain for } 2 \text { yrs }\end{array}$ & gross total & cervical spine RT & $\begin{array}{l}\text { alive \& walking inde pendent } y \text { at } 3 \text { - } \\
\text { yr follow up }\end{array}$ \\
\hline $\begin{array}{l}\text { Stranjalis \& } \\
\text { Torrens, } 1993\end{array}$ & $\begin{array}{l}\text { treast/neck pain \& It hemi- } \\
\text { paresis }\end{array}$ & $\mathrm{CO}_{2}$ laser ablation & preop RT & $\begin{array}{l}\text { signicant improwement; malked \& } \\
\text { li wed independently for } 22 \text { mos; } \\
\text { death at } 24 \text { mos from widespread } \\
\text { disease }\end{array}$ \\
\hline \multirow[t]{3}{*}{ Present study } & $\begin{array}{l}\text { treastdt leg pain, progressive } \\
\text { paraparesis, \& urinary reten- } \\
\text { tion for } 10 \text { days }\end{array}$ & $\begin{array}{l}\text { gross total of tumor } \\
\text { \& cyst inal }\end{array}$ & RTichemo & $\begin{array}{l}\text { recovered from paraparesis but not } \\
\text { urinary retention; well for } 11 \text { mos; } \\
\text { died at } 19 \text { mos }\end{array}$ \\
\hline & $\begin{array}{l}\text { large-cell lung/3-mo hx of } \\
\text { numbness; } 1 \text { mo hx of ataxia } \\
\& \text { LE weakness; dense hemi- } \\
\text { paresis }\end{array}$ & subtotil & none & $\begin{array}{l}\text { able to ambulate until death at } 6 \text { mos } \\
\text { from complications of primary } \\
\text { tumor }\end{array}$ \\
\hline & $\begin{array}{l}\text { oat-cell carcinoma kapidl y pro- } \\
\text { gressive paraparesis, bomel \& } \\
\text { uladder incontinence }\end{array}$ & gross subtotal & none & $\begin{array}{l}\text { regained bowel } \& \text { bladder function at } \\
1 \text { meek; walking at Day } 4 \text {; death } \\
\text { from primary tumor at } 8 \text { mos }\end{array}$ \\
\hline
\end{tabular}

"chemo $=$ chemotherapy (= cyclophosphamide, methotre sate, 5 -fluorouracil); CUSA = Cavitron ultrasonic suction aspirator; hx = history; LE = lo mer extrem ity; $R T=$ radiation therapy.

Several factors are important when considering surgical treatment. The patient's age and physical condition affect candidacy for any surgical treatment. The location and severity of the primary neoplasm, as well as other metastases, weigh heavily in evaluating the prognosis, as well as anesthetic and surgical risks. The physician should also consider the clinical "phase" of the patient's disease. Phase 1 diagnoses are rare, and surgical treatment of asymptomatic cord lesions is of uncertain benefit, considering the risks. Phase 2 can be extremely short and therefore surgical intervention must be considered and implemented swiftly if the patient is already suffering from serious neurological deficits. No one has yet addressed surgical intervention during phase 3 , but it is assumed to be of dubious benefit.

The characteristics of the tumor itself should also be considered. Tumors that are known to be highly radioresistant should be considered for surgical intervention. Most ISCM are well encapsulated and some are cystic. Cystic tumors often lend themselves to surgical extirpation because the cystic component often reaches the surface of the cord and can therefore be more easily removed without disruption to normal structures.

Although the number of cases is small, analysis of the data from the surgical literature suggests the efficacy of surgery in the treatment of some patients with ISCM.[5,7,21,25] Only one patient treated with surgery in this series died within 6 months after surgery, and the neurological status of all eight surgical patients improved postoperatively (Table 1). In contrast, the 6-month survival rates of patients treated with radiation and steroid therapies was $20 \%$. [3,4,6,9,12]

Intramedullary spinal cord metastases can be removed safely in many cases. If a tumor is radioresistant and the patient undergoes operation early in phase 2 , our results and those in the literature indicate surgery is the treatment of choice. The role for surgery in phases 1 and 3 is unknown at this time. As screening MR images gain favor in evaluation of metastases, an opportunity may arise to study phase 1 interventions prospectively. 


\section{References}

1. Aoki H, Fujimoto H, Harada K, et al: Intramedullary spinal cord metastases from lung cancer presenting with paraparesis. An autopsied case. Tokushima J Exp Med 39:89-93, 1992

2. Chason JL, Walker FB, Landers JW: Metastatic carcinoma in the central nervous system and dorsal root ganglia. A prospective autopsy study. Cancer 16:781-787, 1963

3. Choucair AK: Myelopathies in the cancer patient: incidence, presentation, diagnosis and management. Oncology 5:25-31, 1991

4. Costigan DA, Winkelman MD: Intramedullary spinal cord metastasis. A clinicopathological study of 13 cases. J Neurosurg 62:227-233, 1985

5. Decker RE, Sundrani S, Citron ML, et al: Intramedullary spinal cord metastases. Treated by complete resection of tumor prior to radiotherapy and chemotherapy. Spine 12:393-395, 1987

6. Edelson RN, Deck MDF, Posner JB: Intramedullary spinal cord metastases. Clinical and radiographic findings in nine cases. Neurology 22:1222-1231, 1972

7. Findlay JM, Bernstein M, Vanderlinden RG, et al: Microsurgical resection of solitary intramedullary spinal cord metastases. Neurosurgery 21:911-915, 1987

8. Fredericks RK, Elster A, Walker FO: Gadolinium enhanced MRI: a superior technique for the diagnosis of intraspinal metastases. Neurology 39:734-736, 1989

9. Grem JL, Burgess J, Trump DL: Clinical features and natural history of intramedullary spinal cord metastases. Cancer 56:2305-2314, 1985

10. Hamilton MG, Tranmer BI, Hagen NA: Supratentorial glioblastoma with spinal cord intramedullary metastasis. Can J Neurol Sci 20:65-68, 1993

11. Holoye P, Libnoch J, Cox J, et al: Spinal cord metastasis in small cell carcinoma of the lung. Radiat Oncol Biol Phys 10:349-356, 1984

12. Jellinger K, Kothbauer P, Sunder-Plassmann E, et al: Intramedullary spinal cord metastases. J Neurol 220:31-41, 1979

13. Kamholtz R, Sze G: Current imaging in spinal metastatic disease. Semin Oncol 18:158-169, 1991

14. Komaki M, Cox JD, Holoye PY, et al: Changes in the relative risk and sites of central nervous system metastasis with effective combined chemotherapy and radiation therapy for small cell carcinoma of the lung. Am J Clin Oncol 6:515-521, 1983

15. Mastaglia FL, Kakulas BA: Intramedullary spinal cord metastasis from mammary carcinoma. Paraplegia 8:14-18, 1970

16. Murphy KC, Feld R, Evans WK, et al: Intramedullary spinal cord metastases from small cell carcinoma of the lung. J Clin Oncol 1:99-106, 1983

17. Nugent JL, Bunn PA, Matthews MJ, et al: CNS metastases in small cell bronchogenic carcinoma: increasing frequency and changing pattern with lengthening survival. Cancer 44:1885-1893, 1979

18. Post MJD, Quencer RM, Green BA, et al: Intramedullary spinal cord metastases, mainly of nonneurogenic origin. AJR 148: $1015-1022,1987$

19. Schwechheimer K, Lemminger JM: Intramedullary metastases: report of 4 cases and review of the literature. Clin Neuropathol 4:28-37, 1985

20. Sebastian PR, Fisher M, Smith TW, et al: Intramedullary spinal cord metastasis. Surg Neurol 16:336-339, 1981

21. Stranjalis G, Torrens MJ: Successful removal of intramedullary spinal cord metastasis: case report. B J Neurosurg 7:193-195, 1993

22. Thomas AW, Simon SR, Evans CA: Intramedullary spinal cord metastases from epithelial ovarian carcinoma. Gynecol Oncol 44:195-197, 1992

23. Tognetti F, Lanzino G, Calbucci F: Metastases of the spinal cord from remote neoplasms. Study of five cases. Surg Neurol 
30:220-227, 1988

24. Weissman DE, Grossman SA: Simultaneous leptomeningeal and intramedullary spinal metastases in small cell lung carcinoma. Med Pediatr Oncol 14:54-56, 1986

25. Winkelmann MD, Adelstein DJ, Karlins NL: Intramedullary spinal cord metastasis. Diagnostic and therapeutic considerations. Arch Neurol 44:526-531, 1987

Manuscript received March 23, 1998.

Accepted in final form April 28, 1998.

Address reprint requests to: Adam S. Arthur, B.A., Cerebrovascular Lab, University of Virginia, Department of Neurosurgery, HSC Box 420, Charlottesville, VA 22908. 